\title{
Environmental Scientiae
}

Jun a Nov $2020-$ v.2 - n.2

\section{0 pagamento por serviços ambientais como alternativa socioeconômica para a gestão dos resíduos sólidos no Amazonas}

O presente estudo tem como objetivo analisar os Pagamentos por Serviços Ambientais (PSA) como alternativa socioeconômica para a gestão dos resíduos sólidos no Amazonas. Inicialmente analisou-se o panorama dos resíduos sólidos no estado do Amazonas sob a ótica da economia, apontando obstáculos sociais, principalmente quanto aos catadores, e por fim, a apliçção do PSA. A metodologia utilizada foi a bibliográfica e documental, utilizando artigos científicos e dados do governo. O panorama de resíduos sólidos urbanos (RSU) no Amazonas é ruim, principalmente pela inexistência de um aterro sanitário no estado. Socialmente, abordou-se a importância dos catadores de materiais recicláveis para o sistema formal da coleta seletiva e reciclagem e suas limitações técnicas e exclusão social. Economicamente, a situação pode ser enfrentada com instrumentos de Comando e Controle (C\&C) e benefícios econômicos. O PSA apresentou-se como alternativa viável para auxiliar a gestão de RSU, devendo atuar principalmente sobre as cooperativas de catadores. Conclui-se que o estado precisa de maiores investimentos nesse item do saneamento básico, podendo utilizar instrumentos econômicos para sua viabilização, contudo, sem excluir os catadores que são fundamentais para o sucesso do sistema.

\section{Payment for environmental services as a socio-economic alternative for Amazonas solid waste management}

This study aims to analyze Payments for Environmental Services (PSA) as a socioeconomic alternative for solid waste management in the Amazonas State. Initially, the solid waste panorama in the Amazonas State was analyzed from the perspective of the economy, pointing out social obstacles, especially regarding waste pickers, and finally, the application of PSA. The methodology used was bibliographic and documentary, using scientific articles and government data. The picture of solid urban waste (MSW) in Amazonas is bad, mainly due to the lack of a landfill in the state. Socially, the importance of recyclable waste pickers for the forma system of selective collection and recycling and its technical limitations and social exclusion were addressed. Economically, the situation can be met with Command and Control (C\&C) instruments and economic benefits. The PSA has presented itself as a viable alternative to help the management of MSW, and should act mainly on the collectors' cooperatives. It is concluded that the state needs greater investments in this item of basic sanitation, being able to use economic instruments for its viability, however, without excluding the pickers that are fundamental to the success of the system.

Keywords: Recycling; Amazonas; Waste pickers; Environmental Services.

Topic: Planejamento, Gestão e Políticas Públicas Ambientais

Reviewed anonymously in the process of blind peer
Received: 02/05/2020

Approved: 29/06/2020
Rodrigo Couto Alves

Universidade Federal do Amazonas, Brasil http://lattes.cnpq.br/5580327610051854 http://orcid.org/0000-0002-7452-9455

rcouto@ufam.edu.br

Henrique dos Santos Pereira (iD

Universidade Federal do Amazonas, Brasil http://lattes.cnpq.br/1352117560279931 http://orcid.org/0000-0002-9113-1166

henrique.pereira.ufam@gmail.com
Referencing this:

ALVES, R. C.; PEREIRA, H. S.. O pagamento por serviços ambientais como alternativa socioeconômica para a gestão dos resíduos sólidos no Amazonas. Environmental Scientiae, v.2, n.2, p.12-24, 2020. DOI: http://doi.org/10.6008/CBPC2674-6492.2020.002.0002 


\section{INTRODUÇÃO}

A geração de resíduos sólidos urbanos (RSU) é um dos problemas mais agravantes da sociedade contemporânea, reforçado pelo crescimento gradativo e desordenado da população, pela aceleração do processo de ocupação do território urbano e pelo crescimento acentuado dos bens de consumo popularizados pelo aumento da produção industrial. Quando coletados e tratados inadequadamente, podem provocar efeitos controversos na saúde humana e ao meio ambiente (KUWAHARA, 2014).

Segundo Fraxe et al. (2011), o lixo, ou resíduo sólido, possui um significado onde se prevalece a dimensão cultural e esta nos permite entender o conceito de lixo como algo instituído historicamente, sempre associado a "coisa suja", "doença", "podridão". O advento da Política Nacional de Resíduos Sólidos (PNRS), estabelecida pela Lei no 12.305, de 02 de agosto de 2010 e regulamentada pelo Decreto $n=7.404$, de 23 de dezembro de 2010, marcou um grande avanço ao desenvolvimento sustentável, estabelecendo diretrizes e instrumentos para a gestão dos resíduos sólidos no Brasil.

O Decreto 7.404/2010, criou o Comitê Interministerial da Política Nacional de Resíduos Sólidos, que tem dentre outras finalidades, busca incentivar e viabilizar a implantação de instrumentos econômicos e de comunicação como incentivos fiscais, financeiros e creditícios voltados à pesquisa científica e tecnológica e à educação ambiental, assim como prioriza a participação de cooperativas e associações de catadores de materiais recicláveis nos sistemas de coleta seletiva e reciclagem.

O presente estudo buscou discutir sobre o panorama dos resíduos sólidos no estado do Amazonas, discutindo os aspectos sociais que aborda esse tema, especificamente, sobre os catadores de materiais recicláveis, assim como identificando possíveis alternativas econômicas para a equalização da problemática do volume de geração e disposição final inadequada, destacando os pagamentos por serviços ambientais.

A metodologia utilizada tem caráter de revisão bibliográfica, pois foram contemplados materiais publicados em livros, revistas, artigos científicos, dissertações, teses e periódicos para o embasamento teórico, sendo que o material foi coletado no período de maio a junho de 2019. O uso de trabalhos científicos como artigos, teses e dissertações justifica-se por oferecerem discussões mais atuais do objeto de estudo. Possui também caráter documental ao ter acessado informações contidas em documentos primários e originais, bem como documentos disponibilizados por empresas e órgãos do governo.

Verificou-se que o panorama dos resíduos sólidos no Amazonas é negativo, considerando que nenhum município do estado possui aterro sanitário e que somente a capital, Manaus, possui um aterro controlado. O estado também possui a maior geração per capita de RSU em toda região norte. Aponta-se como alternativas econômicas para a equalização desta problemática, instrumentos de C\&C e benefícios econômicos. Entende-se que os catadores de materiais recicláveis são agentes fundamentais para a coleta seletiva e reciclagem dos RSU no estado, contudo, eles encontram-se no mercado informal, sendo necessário incluí-los no sistema tornando-os protagonista do sistema.

Logo, o PSA torna-se um instrumento econômico fundamental para a equalização dos problemas ambientais da gestão de RSU no Amazonas, ao mesmo tempo que resgata a cidadania dos catadores de 
materiais recicláveis possibilitando o mesmo advir ao mercado da reciclagem com o mínimo de valorização.

\section{METODOLOGIA}

O desenvolvimento do estudo está estruturado em quatro subtópicos que abordarão sobre o panorama dos resíduos sólidos no Amazonas, os aspectos sociais referentes a atuação dos catadores de materiais recicláveis, os instrumentos econômicos de Comando e Controle (C\&C) e benefícios econômicos e por fim, sobre os pagamentos por serviços ambientais (PSA).

\section{DISCUSSÃO TEÓRICA}

\section{Panorama dos Resíduos Sólidos no Amazonas}

No Brasil, o advento da Política Nacional de Resíduos Sólidos (PNRS), estabelecida pela Lei no 12.305/2010 e regulamentada pelo Decreto no 7.404/2010, marcou um grande avanço das políticas públicas nacionais em prol do desenvolvimento sustentável, ao estabelecer as diretrizes e os instrumentos para a gestão dos resíduos sólidos no país, além de apresentar vários instrumentos e metas para serem alcançados até 2014 (BRASIL, 2010). Com o intuito de promover a disposição final ambientalmente adequada a política estabelece, em seu artigo 54, a erradicação dos lixões em até 4 (quatro) anos, meta que não foi alcançada e continua em fase de prorrogações com propostas para até o ano de 2021 (BRASIL, 2017).

Dentro desse contexto, o Estado do Amazonas, mesmo com a Política Estadual de Resíduos Sólidos do Amazonas (PERS/AM), estabelecida pela Lei no 4.457, de 12 de abril de 2017, se apresenta como um dos grandes geradores de resíduos sólidos urbanos (RSU) da região norte do país (ALEAM, 2017) e, de seus 62 municípios, apenas um não dispõe seus RSU em lixões (ALEAM, 2018). Esse quadro é acompanhado pela maioria dos municípios da Amazônia brasileira (BRASIL, 2016), onde os municípios apresentam dificuldades em equalizar esse problema.

Segundo dados da Assembleia Legislativa do estado do Amazonas (ALEAM, 2017), o estado tem uma geração per capita de 1,156 kg/habitante/dia, o maior do Norte. Os dados da ALEAM também apontam que no estado, a coleta dos resíduos foi de 0,936 kg por habitante, ou seja, ainda não há a universalização da coleta de RSU. A falta de recursos financeiros e materiais no interior do Estado do Amazonas é um dos aspectos que mais inviabiliza a gestão eficiente de resíduos sólidos de forma isolada, ocasionando a dificuldade na erradicação dos seus lixões (AMAZONAS, 2015).

Segundo Cardoso Filho (2014), a gestão dos RSU no município de Parintins não atende também o que determina a PNRS. Alguns desafios precisam ser superados, como: implantação do sistema de coleta seletiva e de logística reversa, melhorias na infraestrutura da Associação dos Catadores de Parintins, destinação e disposição final, ambientalmente adequada dos diversos tipos de resíduos, mitigação dos impactos ambientais, maior participação social nas ações de educação ambiental, dentre outros.

O município de Coari, localizado no Médio Solimões, encontra-se em situação similar. Mota (2014) aponta a necessidade de desencadear ações voltadas para a gestão de resíduos junto à população e defende 
que a problemática dos RSU não deve ficar limitada ao departamento público específico, mas sim, como determinar a PNRS, é responsabilidade de todos.

O município de Tefé apresentou um problema, segundo estudos de Silva (2009), bem comum nos municípios do estado: falta de malha rodoviária. Esse problema, em particular, dificulta a seleção de áreas passíveis de receber os rejeitos (aterros sanitários). $O$ autor alega que esse problema também afeta outros municípios do estado.

Essa alegação é confirmada pela ALEAM (2017), no que seu relatório apresenta dados do TCE que aponta para a falta de controle na gestão dos RSU; deficiência na coleta e no transporte; a falta de capacitação técnica nas prefeituras; a descontinuidades das ações durante os mandatos subsequentes e à seleção da área para a implantação de aterros sanitários sem nenhum estudo prévio.

Não somente os municípios do interior têm problemas de gestão de resíduos sólidos, mas essa problemática pode ser visualizada também em Manaus, principalmente em seu Polo Industrial (PIM). Meireles (2016), em seu estudo sobre os resíduos plásticos no PIM, verificou que a inexistência de um sistema eficiente de gestão e controle dos resíduos pós-geração.

Segundo a autora, o PIM carece de pesquisas para estruturação de sistema de gestão de resíduos eficiente que atenda às necessidades e características regionais e para retroalimentação do mercado de reciclagem que incentive o desenvolvimento socioeconômico e ambiental. Ainda em Bezerra et al. (2013), afirmam que no Plano Diretor da cidade as responsabilidades pela gestão dos resíduos sólidos são terceirizadas, mas que a responsabilidade principal sempre será da administração pública, e que o aumento contínuo da população, e, consequentemente, o aumento da geração de resíduos é um dos principais problemas ambientais enfrentados pelas prefeituras do Amazonas.

Nas comunidades ribeirinhas a questão dos resíduos também é presente, principalmente, quanto à educação ambiental. Bacelar (2016) realizou um estudo em uma comunidade isolada no Amazonas, onde buscou implantar um biodigestor para o tratamento dos resíduos orgânicos. Ele concluiu que mesmo com o treinamento ministrado, o acompanhamento, a aquisição do informativo, percebeu que não houve um total engajamento por parte das famílias.

Contudo, ele aponta que, daqueles que perceberam a importância da proposta, houve avanços, como: relações interpessoais entre as famílias quanto a distribuição dos adubos; algumas famílias começaram a construir canteiros planejando comercializar os adubos; diminuição dos resíduos descartados inadequadamente, entre outros. É importante frisar que não basta somente intervir em uma comunidade ou município com os instrumentos da PNRS, é necessário que haja uma imersão na cultura local para que a implantação de tais instrumentos seja concluída com êxito, observando as peculiaridades de cada local.

\section{Aspectos Sociais: o desafio dos catadores de materiais recicláveis}

Segundo Kuwahara (2014), a PNRS inova ao focar a coleta seletiva e a reciclagem com a inclusão socioprodutiva de catadores de materiais recicláveis, organizados em associações ou cooperativas de trabalho. A lei criou instrumentos para estimular os municípios a envolverem as cooperativas e associações 
desses catadores no sistema de gerenciamento de resíduos sólidos.

Contudo, Jardim et al. (2012) alega que a PNRS por si só não gera benefício pois, infelizmente, o nosso país é repleto de leis e regulamentos que não são seguidos. Ainda segundo o autor, a PNRS teria condicionado o fechamento dos lixões à inclusão social e à emancipação econômica dos catadores e catadoras que trabalham e tiram seu sustento nesses locais. A lei não pode ser um mecanismo de exclusão social nem fonte de novos negócios lucrativos.

No estado do Amazonas existem associações de catadores de resíduos sólidos que funciona nas atividades correspondentes desde a coleta, até a produção de fardos, tendo a comercialização como produto (FRAXE et al., 2011). Ainda segundo os autores, as questões enfrentadas pela cidade de Manaus requerem mudanças de paradigmas, tanto individuais, como coletivas, e no âmbito privado e público. A reciclagem propicia vários benefícios ambientais como o reaproveitamento dos materiais descartados, economia de recursos naturais, água e energia, e inclui vantagens sociais ao absorver os catadores de materiais recicláveis no seu ciclo produtivo (MEIDEIROS et al., 2006).

Os catadores, mesmo em sua minoria e através do trabalho cooperativo, já compreendem que podem ser reconhecidos como sujeitos de direitos e deveres, rejeitando o estigma negativo da classe (GOMES, 2014). Eles estarão à frente da luta para a implantação da coleta seletiva, pois aprenderam no processo de reconhecimento do seu trabalho, que seu ofício não é apenas mas para si, mas para toda uma geração que está por vir (JARDIM et al., 2012).

Os catadores trabalham com a finalidade de prestar serviços à sociedade e ao meio ambiente (JARDIM et al., 2012). Sua organização acontece determinada pelo capital envolvido no negócio da reciclagem, embora a relação social de exploração sobre o trabalho não apareça formalizada em contratos que fixem jornadas e salários (BOSI, 2008).

Os catadores, como uma categoria social, desenvolvem suas atividades sob as mais adversas condições (FRAXE et al., 2011) e em situação de risco dada a insegurança e a insalubridade (JARDIM et al., 2012). Segundo Kuwahara (2014) existe uma vasta tipologia de catadores e organizações que precisam ser compreendidas e que requerem políticas públicas diferenciadas. Já Meideiros et al. (2006) afirma que os catadores são excluídos do mercado de trabalho e, para manterem sua sobrevivência, voltam-se a situações precárias da catação, contudo, sentem-se incluídos no mercado da reciclagem.

Meideiros et al. (2006) afirma que existe inclusão negativa, pois além dessas condições nãoapropriadas de trabalho, os lucros dessas categorias são muito baixos visto que não negociam diretamente com as grandes empresas de reciclagem, mas sim com os intermediários. Logo, é necessário, visando a sobrevivência dessas pessoas depende exclusivamente da intervenção do poder público, o qual deve estar à frente das ações de assistência e inclusão social, além da construção de galpões, compra de equipamentos e capacitação técnica (JARDIM et al., 2012).

Contudo, segundo Kuwahara (2014), a contratação das organizações ainda não foi incorporada enquanto prática, colocando a maioria dessas iniciativas no âmbito de projetos ambientais e de inclusão social, e quando oficializadas, acontecem por meio de convênios. A fragilidade econômica abre caminho para 
a exploração de pequenos e médios empresários que se utilizam da mão de obra barata e sem vínculos empregatícios dos catadores para a compra dos recicláveis por preços irrisórios (JARDIM et al., 2012). Contudo, Bosi (2008) argumenta que essas ocupações vêm ganhando relevância no mundo do trabalho exatamente porque têm sido acionadas como forma de produção preferencial do capital e não como escolha exclusiva dos trabalhadores.

A catação de resíduos organizada tem demonstrado possibilidades de um caminho possível para a superação da exclusão e construção de cidadania (FRAXE et al., 2011). E não somente isso, além de sua inclusão, o processo aponta para uma resignificância no olhar da sociedade para esses grupos que necessitam de maior participação nos assuntos políticos e econômicos quanto às questões dos recursos ambientais, às suas inserções nos processos de democratização, confirma afirma Leff (2006).

A inclusão dos catadores no sistema formal de coleta seletiva precisa ser realizada de forma cautelosa, respeitando a outridade. Leff (2006) afirma que é preciso aprender com o diferente, com o outro (nesse caso o catador), pois estamos limitados com o igual. Logo, precisamos entender quais as necessidades, direitos e deveres dos catadores sob sua própria ótica.

Segundo Fraxe et al. (2011) é necessário que se consuma menos e que se reparta melhor. No que diz a consumir menos, pressupõe-se adotar novas estratégias ao que antecede a produção, enquanto repartir melhor compreende a inclusão social dos catadores de materiais recicláveis. É preciso enxergá-los for a do olhar estigmatizante daqueles que os viam como cidadãos de categoria inferior.

\section{Alternativas Econômicas: soluções para a problemática dos resíduos?}

A contraproposta imediata é investir na reciclagem dos resíduos, que apesar dos custos (energia e água), consegue recuperar e reprocessar o material evitando a perda de matéria-prima e a disposição desnecessária nos lixões (MEIRELES, 2016). A reciclagem apresenta-se como uma alternativa para diminuição dos impactos ambientais ocasionados pela geração de resíduos sólidos assim como uma fonte de renda para os cidadãos. Contudo, uma etapa essencial para a essa atividade é ter um sistema eficiente de coleta seletiva. O estado do Amazonas tem uma considerável geração de resíduos sólidos e a inexistência do sistema de coleta seletiva e consequentemente baixíssima taxa de recuperação de materiais recicláveis, que são dispostos, em sua maioria, no lixão municipal.

Os principais benefícios ambientais da reciclagem dos materiais existentes no são: a economia de matérias-primas não-renováveis; a economia de energia nos processos produtivos; o aumento da vida útil dos aterros sanitários. O grande desafio para implantação de programas de reciclagem é buscar um modelo que permita a sua sustentabilidade econômica. Os modelos mais tradicionais, implantados em países desenvolvidos, quase sempre são subsidiados pelo poder público e são de difícil aplicação em países em desenvolvimento (MONTEIRO, 2001).

Existe duas falhas de mercado que podem explicar o motivo da reciclagem não funcionar no Amazonas: a informação imperfeita e as externalidades. A informação imperfeita, ou assimetria de informação, como falha de mercado, ocorre quando o consumidor ou o produtor não conhecem todos os 
custos ou benefícios associados ao bem ou à atividade (RIVAS, 2014). Dessa maneira, o sistema de Mercado não pode operar eficientemente pois os produtores podem ofertar quantidades excessivas de um produto enquanto outros produtos terão baixas ofertas. O mesmo ocorre com o consumidor que pode, ou comprar um produto que não o beneficie, ou comprar um produto que possa lhe causar prejuízos futuros (PINDYCK, 2010).

Quanto à geração de resíduos sólidos, a informação imperfeita, ocasiona o descarte incorreto deles. Os materiais recicláveis são descartados inadequadamente devido os consumidores não terem conhecimento que ele é reciclável ou por não possuir conhecimento de locais para depositar o material. O baixo número de municípios que informam ao menos o que pode ou não pode ser separado para coleta seletiva pode reduzir o desempenho desse serviço público, aumentando a quantidade de rejeitos e a assimetria da informação à população (KLEIN et al., 2018).

Quanto à externalidade, essa falha ocorre quando uma atividade de produção ou de consumo possui um efeito indireto sobre outras atividades similares, que não se reflete diretamente nos preços de mercado, sendo que esse efeito é externo ao mercado (PINDYCK, 2010). A externalidade surge quando uma pessoa se dedica a uma ação que provoca impacto no bem-estar de um terceiro que não participa dessa ação, sem pagar nem receber nenhuma compensação por esse impacto (MANKIW, 2009). A geração de resíduos sólidos é uma externalidade da consequência produção industrial local e oriunda da limpeza pública.

Considerando o exposto, surge a necessidade de equalizar essa externalidade, sendo através de instrumentos de Comando \& Controle (C\&C) ou através de benefícios econômicos. Pigou (1920) argumenta que a aplicação de impostos é necessária para que a divergência entre os custos privados e sociais sejam amenizados, ou seja, a coerção por parte do governo para corrigir essa falha de mercado.

Em contrapartida, Coase (1960) apresenta uma abordagem diferente, utilizando benefícios econômicos com o intuito de seguir a alternativa com prejuízo menos severo. A partir do seu estudo, surgiu o Teorema de Coase que em geral, implica na negociação, sem custos de transação, dos entes afetados para a internalização das perdas causadas pelas externalidades.

As externalidades são possivelmente as falhas de mercado mais comuns na área da economia ambiental e não há somente externalidades negativas, mas também positivas (RIVAS, 2014). Essas externalidades surgem quando as ações de alguns indivíduos têm efeitos diretos sobre o bem-estar ou utilidade de outros indivíduos, nenhum dos quais tem controle direto sobre essa atividade, ou seja, externalidades são benefícios incidentais ou custos para outros os quais eles não são pretendidos (HUSSEN, 2004).

Quanto às duas falhas de mercado, sugere-se a intervenção do Estado com alternativas vinculadas tanto ao C\&C como aos benefícios econômicos. A intervenção do governo para corrigir as externalidades negativas, pode dar-se por meio de produção direta do bem ou concessão de subsídio as empresas fabricantes; de multas ou tributos aos agentes que causam danos a sociedade; ou ainda, através da regulamentação das atividades que apresentam resultados negativos a população.

As licenças ambientais, instrumento de C\&C, podem auxiliar na equalização de ambas as falhas. 
Quanto a assimetria de informações, os processos de licenciamento ambiental podem exigir, dentro do escopo de documentos, a inserção da rotulagem ambiental. Esse mecanismo de rotulagem ambiental apresenta-se como uma alternativa, pois baseiam-se em informações disponibilizadas nos rótulos de embalagens para que os consumidores possam optar por adquirir produtos de menor impacto ambiental em relação aos produtos concorrentes disponíveis no mercado (MOURA, 2013).

Quanto a externalidades, os licenciamentos podem exigir, dependendo do grau de poluidor, análises ou programas de gerenciamento e monitoramento das emissões causadas pelos agentes poluidores, sendo que as próprias taxas do licenciamento buscam internalizar esses custos. A utilização de licenças ambientais é uma alternativa para internalizar o custo ocorrente da falha. Esse instrumento é usado pelos órgãos de controle ambiental para permitir a instalação de projetos e atividades com certo potencial de impacto ambiental (MARGULIS, 1996).

Quanto ao benefício econômico, um instrumento que poderia ser utilizado seria o depósitoreembolso. Na definição de Nusdeo (2016),

Os sistemas de depósito e reembolso baseiam-se na cobrança de um depósito compulsório pelo consumidor ao adquirir produtos que impliquem resíduos sólidos tóxicos e de difícil tratamento, que lhe é reembolsado se o consumidor o entregar em postos de coleta após seu uso. Trata-se de um sistema interessante para a gestão de resíduos como pilhas, pneus e embalagens de agrotóxicos. A destinação final desses resíduos no Brasil é objeto de disciplina legal que obriga os consumidores e fabricantes ao recolhimento do produto ou da embalagem após seu uso, mas não há previsão de depósito e reembolso.

Esse sistema é uma forma eficientemente de controle de externalidades negativas, sendo que tal sistema se assemelha a um imposto, mas em vez de fazer com que o cidadão pague pelos efeitos indesejáveis, atua no sentido de recompensá-lo por ter contribuído antecipadamente com uma atitude ambientalmente sustentável (RIVAS, 2014).

Esses sistemas fazem com que os consumidores paguem um depósito de certo valor sempre que comprarem produtos potencialmente poluidores. Quando devolvem os produtos usados a centros autorizados de reciclagem ou reutilização, recebem seu depósito de volta. São geralmente usados para os seguintes materiais recicláveis: latas de alumínio, baterias, embalagens de agrotóxicos, vidros e outros (MARGULIS, 1996).

\section{Pagamento por Serviços Ambientais na Gestão de Resíduos Sólidos}

Entretanto, existe outro instrumento econômico que permite a equalização da problemática do RSU no Amazonas: o Pagamento por Serviços Ambientais (PSA). O PSA ainda não possui uma política nacional promulgada, apesar que no projeto de lei já está em trâmite no congresso.

Existem divergências a respeito do conceito de Serviços Ambientais na comunidade científica, conforme aponta Pereira et al. (2014). Segundo os autores, observa-se que o conceito é diferente inclusive em cada política estadual e os mesmos adotam como a definição mais correta a que os serviços ambientais são aqueles providos ao ambiente pelo homem.

O Projeto de Lei no 5.028/2019 institui a Política Nacional de Pagamento por Serviços Ambientais, e 
nesta os serviços ambientais são definidos como: "atividades individuais ou coletivas que favorecem a manutenção, a recuperação ou a melhoria os serviços ecossistêmicos". Já os serviços ecossistêmicos podem ser definidos, segundo Pereira et al. (2014), como: "as contribuições oriundas do funcionamento dos ecossistemas, das características, funções ou processos ecológicos que indiretamente contribuem para a vida e o bem-estar humano".

O contexto atual dos RSU traz à tona a importância do trabalho dos catadores de materiais recicláveis, principalmente no estado do Amazonas, que possui deficiências nos sistemas de gestão de RSU. O arcabouço legal para a integração dos catadores na gestão dos RSU já está constituído, restando ao poder público definir quais os principais incentivos para atender a demanda desses agentes como da problemática dos RSU (RIBEIRO et al., 2014).

Segundo Lima et al. (2018), para uma correta gestão ambiental dos resíduos sólidos, o Estado deve promover políticas públicas que corrijam as externalidades resultantes das padrões de consumos insustentáveis, sendo que os projetos de PSA não podem substituir essas políticas públicas nem quaisquer investimentos sociais visando a redução da pobreza (MORAES, 2012).

A aplicação do PSA na gestão dos resíduos sólidos traz benefícios sociais, econômicos e ambientais, mesmo esses últimos sendo mais difíceis de valorar. $O$ instrumento viabiliza a manutenção e desenvolvimento de coleta seletiva, triagem e até disposição final de RSU (FERNANDES et al., 2017). Segundo Souza Júnior (2018), é possível aplicar o PSA através da iniciativa privada com vistas ao desenvolvimento sustentável. $\mathrm{O}$ autor afirma que o instrumento viabiliza a inserção dos catadores do processo produtivo da reciclagem além de cumprir com os requisitos estabelecidos pela PNRS.

Há um entendimento que a atividade da reciclagem é um serviço ambiental, e nesse sentido, somente pelo fato de os catadores executarem suas atividades, estão realizando um serviço ambiental (BARBOSA, 2015). Ainda segundo o autor, não é possível identificar apenas uma atividade de serviços ambientais prestadas pelos catadores, mas sim um conjunto de atividades simultâneas.

Segundo Ribeiro et al. (2014), deve-se ter cautela na inserção dos catadores na cadeia de comercialização de materiais recicláveis quanto à construção de políticas públicas voltada à inclusão social. O pagamento por serviço ambiental possui, inicialmente, um caráter socialmente assistencial aos catadores de materiais recicláveis, entretanto, deve ao longo do tempo permitir que eles possam desenvolver-se como empreendedores (LIMA et al., 2018).

Os catadores, ao trabalharem de modo informal, acabam incentivando um mercado intermediário de compradores de materiais recicláveis, que por sua vez, estão submetidos às empresas de reciclagem, de modo que os lucros são irrisórios para as cooperativas, diminuindo as expectativas de melhoria de vida (AMARO et al., 2013). Logo, faz-se necessária a implantação de políticas públicas no estado para aproximar as recicladoras das cooperativas, eliminando os intermediários e, consequentemente, aumentado a renda dos catadores.

Um exemplo da aplicação do PSA foi o de Minas Gerais que segundo Ribeiro et al. (2014), após vários avanços na gestão de resíduos sólidos após a promulgação de sua política estadual de RSU, propôs o 
pagamento pelos serviços ambientais executados pelos catadores de materiais recicláveis: a Bolsa Reciclagem. Esse programa consiste em um incentivo financeiro às cooperativas de catadores pela coleta e comercialização dos materiais recicláveis.

Dutra et al. (2018) verificaram que essa Bolsa Reciclagem implantada em Minas Gerais contribuiu com a melhoria no rendimento e desenvolvimento administrativo das cooperativas, com o incentivo à reciclagem dos resíduos. Contudo, apesar da melhoria do rendimento, houve uma redução considerando o

Outro exemplo aplicado são os Pagamentos por Serviços Ambientais Urbanos (PSAU). Borges (2017) e Altmann (2015) afirmam que o PSAU possui aplicabilidade e pode ser um instrumento positivo para a gestão dos RSU. Contudo, como o princípio de protetor-recebedor é algo novo no Brasil, o que se viu foi ações pontuais com benefícios orientados pelos preços do mercado que não refletem o custo marginal do provimento peo serviço ambiental. O PSAU também contribui para a diminuição da exclusão social e proporciona benefícios econômicos e socioambientais para as cooperativas de catadores (MACHADO, 2017).

A PERS-AM, em art. 4, inciso XIV, apresenta como um de seus instrumentos o pagamento por serviços ambientais, em conformidade com a legislação pertinente. Contudo, o panorama estadual está muito aquém do necessário para uma boa gestão dos RSU. Problemas de infraestrutura, governança, financeiros e de recursos humanos estão presentes no sistema de gestão de RSU no Amazonas, retirando a prioridade da implantação de um PSA que contemple os catadores, e por consequência, o sistema todo.

\section{CONCLUSÕES}

A geração e o acúmulo de resíduos sólidos têm ocasionado a escassez dos recursos naturais, a degradação do meio ambiente e o esgotamento das áreas físicas para a armazenagem/disposição dos resíduos sólidos (MEIDEIROS et al., 2006). Essa realidade pode ser visualizada no estado do Amazonas, onde nenhum dos municípios do estado possui um sistema de disposição final ambientalmente adequada.

Apesar dos avanços que a PNRS trouxe no país, ainda existem grandes desafios a serem enfrentados, como a inclusão dos catadores avulsos e a dependência das organizações de catadores de políticas públicas (KUWAHARA, 2014). A inserção desses agentes na cadeia de comercialização de recicláveis deve ser observada atentamente quando da confecção de uma política voltada à inclusão social.

Ressalta-se que apesar de todas as dificuldades vividas pelos catadores tanto em nível material, quanto nas fragilidades subjetivas, é fato que eles resistem, a sua maneira ao processo de exclusão/inclusão, a que estão submetidos. O papel do catador na cadeia econômica do RSU precisa ser reconhecido e é necessária uma melhor organização de seu trabalho em cooperativas, associações e outras formas que lhe permita atuar em rede para a construção de uma identidade coletiva.

Com relação ao processo de tomada de decisão sob a ótica econômica, o agente econômico deve escolher uma alternativa frente a uma diversidade de opções e para isso são necessários instrumentos analíticos confiáveis. Para que os instrumentos do tipo C\&C possam funcionar com eficácia, os papéis regulador e policial dos governos precisam funcionar em associação.

O sucesso desse sistema dependerá quase exclusivamente da capacidade que o órgão de controle 
ambiental tiver para assegurar a obediência à lei, ou seja, fazer os poluidores se conformarem com os padrões e punir os infratores, e do poder político que o setor tiver para resistir às eventuais ações legais movidas pelos agentes econômicos, contestando suas iniciativas.

Contudo, a variação econômica do bem-estar do cidadão não seria compensada na eventual implantação da coleta seletiva, portanto, torna-se necessário que o governo municipal observe os custos marginais da adoção desse sistema e como os contribuintes reagem economicamente com relação à sua disposição para pagar pelo serviço.

O PSA apresenta-se como um instrumento econômico alternativo para auxiliar na gestão dos RSU no Amazonas. Como a PNRS e a PERS-AM incentivam a inclusão destes na respectiva gestão, os pagamentos pelos serviços prestados por eles garantiriam a sua permanência no sistema, além de melhorar a qualidade de vida destes e a diminuição dos impactos ambientais gerados pelos RSU. Contudo, sem uma política estabelecida a nível nacional e uma estadual que não prevê a inserção destes no PSA, além de uma indefinição do próprio conceito, trazem dificuldades para a implantação dele. Será necessário a revisão do arcabouço legal para dar garantias a estes agentes ambientais.

A problemática dos resíduos, em especial nos grandes centros urbanos, constitui-se num sério problema por envolver aspectos sociais, ecológicos e econômicos, sendo que somente o bom senso, aliado aos recursos da ciência e da tecnologia podem resolvê-lo satisfatoriamente. Logo, é necessário aplicar os instrumentos econômicos, tanto de C\&C, como os benefícios econômicos, principalmente o PSA, para melhorar o atual sistema de gerenciamento de RSU. Entende-se que os catadores de materiais recicláveis são peças fundamentais para a eficácia da reciclagem no estado assim como é necessário retirá-los da margem e incluí-los como protagonista do sistema de gerenciamento de RSU no estado do Amazonas.

\section{REFERÊNCIAS}

ALEAM. Assembleia Legislativa do Estado do Amazonas. Amazonas tem um aterro controlado e 61 lixões a céu aberto, diz GT do Saneamento. Manaus: ALEAM, 2018.

ALEAM. Assembleia Legislativa do Estado do Amazonas. Limpeza urbana e manejo de resíduos sólidos. Relatório do Grupo de Trabalho do Saneamento Básico. Parte III. Manaus: ALEAM, 2017.

ALTMANN, A.. Pagamento por serviços ambientais como instrumento de incentivo para os catadores de materiais recicláveis no Brasil. Revista de Direito Ambiental, v.1, p.477-505, 2015.

AMARO, A. B.; VERDUM, R.. Análise dos Serviços Ambientais dos Catadores de Materiais Recicláveis. 2013.

AMAZONAS. Versão 1.0 do Plano Estadual de Resíduos Sólidos do Amazonas: SDS/Laghi Engenharia Ltda./Governo do Estado do Amazonas. Manaus, 2015.

AMAZONAS. Lei n. 4.457, de 12 de abril de 2017. Institui a Política Estadual de Resíduos Sólidos do Amazonas PERS/AM, e dá outras providências. Manaus: DOE, 2017.
BACELAR, F. S.. Reutilização de resíduos sólidos em uma Comunidade isolada no Amazonas. Dissertação (Engenharia de Produção) - Universidade Federal do Amazonas, Manaus, 2016.

BARBOSA, J. C.. Pagamento por serviços ambientais para catadores de material reciclável: oportunidade e desafios. Tese (Doutorado em Ciências Ambientais) - Universidade Federal de Goiás, Goiânia, 2015.

BEZERRA, M. R. V.; STROSKI, A. A.. Manual de Combate aos lixões. Manaus: SDS, 2013.

BORGES, L. D.. Pagamento por serviços ambientais no meio urbano: governança de resíduos sólidos no Distrito Industrial. Monografia (Especialização em Análise Ambiental e Desenvolvimento Sustentável) - Centro Universitário de Brasília, Brasília, 2017.

BOSI, A. P.. A organização capitalista do trabalho 'informal': $\mathrm{O}$ caso dos catadores de recicláveis. Revista Brasileira de Ciências Sociais, São Paulo, v.23, n.67, 2008.

BRASIL. Decreto n. 7.404, de 23 de dezembro de 2010. Regulamenta a Lei no 12.305, de 2 de agosto de 2010, que 
institui a Política Nacional de Resíduos Sólidos, cria o Comitê Interministerial da Política Nacional de Resíduos Sólidos e o Comitê Orientador para a Implantação dos Sistemas de Logística Reversa, e dá outras providências. Brasília: DOU, 2010.

BRASIL. Lei n. 12.305, de 2 de agosto de 2010. Institui a Política Nacional dos Resíduos Sólidos. Brasília: DOU, 2010.

BRASIL. Senado Federal. Projeto de Lei 5.028/2019. Institui a Política Nacional de Pagamento por Serviços Ambientais; altera as Leis nㅇ 8.629 , de 25 de fevereiro de 1993, e 8.212, de 24 de julho de 1991; e dá outras providências. Brasília: DOU, 2019.

BRASIL. Plenário pode votar urgência de projeto que prorroga prazo para fim de lixões. Brasília: DOU, 2019.

CARDOSO FILHO, G. T.. Avaliação da Gestão de Resíduos Sólidos Urbanos na cidade de Parintins/AM: desafios e oportunidades à luz da Política Nacional e Resíduos Sólidos. Dissertação (Mestrado em Ciências do Ambiente e Sustentabilidade na Amazônia) - Universidade Federal do Amazonas, Manaus, 2014.

COASE, R. H.. The problem of social cost. Journal of Law and Economics, v.3, p.1-44, 1960.

DUTRA, T. A. P.; MINÉU, H. F. S.. O programa Bolsa Reciclagem em Minas Gerais: contribuições para a receita e organização das cooperativas. In: SEMINÁRIO DE PESQUISA E INOVAÇÃO TECNOLÓGICA, 2. Anais. Uberaba: IFTM, 2018.

FERNANDES, P. R.; ROCHA, P. C.. Pagamento por serviços ambientais para cooperativas de catadores de materiais recicláveis: cooperativa de catadores da Estância Turística de Olímpia. In: FÓRUM INTERNACIONAL DE RESÍDUOS SÓLIDOS, 8. Anais. Curitiba: FIRS, 2017.

FRAXE, T. J. P.; GENTIL, D. F. O.; ANDRADE, J. B. L.; SILVA, M. A. P.. Papel para a vida: estudo da cadeia produtiva de embalagens de papelão no Polo Industrial de Manaus (PIM). Manaus: FUA, 2011.

GOMES, L. C. M.. Lixo e Cidadania: catadores de materiais recicláveis do aterro metropolitano de Jardim Gramacho. Recife, 2014.

HUSSEN, A. M.. Principles of Enviromental Economics. 2 ed. London: Routledge, 2014.

JARDIM, A.; YOSHIDA, C.; MACHADO FILHO, J. V.. Política Nacional, Gestão e Gerenciamento de resíduos sólidos. Barueri: Manole, 2012.

KLEIN, F. B.; GONÇALVES-DIAS, S. L. F.; JAYO, M.. Gestão de resíduos sólidos urbanos nos municípios da Bacia Hidrográfica do alto Tietê: uma análise sobre o uso do TIC no acesso à informação governamental. Revista Brasileira de Gestão Urbana, v.10, n.1, p.140-153, 2018.

KUWAHARA, M.. Resíduos Sólidos, Desenvolvimento Sustentável e Qualidade de Vida. In: MENEZES, R. T.; SAIANI, C. C. S.; JÚNIOR, R. T.; SAIANI, C. C. S.; DOURADO, J.. Resíduos Sólidos no Brasil: oportunidades e desafios da lei federal no 12.305 (lei de resíduos sólidos). Barueri: Minha, 2014. p.383-420.
LEFF, E.. Racionalidade Ambiental: a reapropriação social da natureza. Rio de Janeiro: Civilização Brasileira, 2006.

LIMA, I. W. P. O.; FARIAS, T.. O pagamento por serviços ambientais aos catadores: instrumento de efetivação da Política Nacional de Resíduos Sólidos. Revistas Direitos Culturais, Santo Ângelo, v.13, n.31, p.407-427, 2018.

MACHADO, K. C.. Pagamento por serviços ambientais como instrumento aliado à gestão de resíduos sólidos: um estudo de caso. Monografia (Especialização em Direito Ambiental Nacional e Internacional) - Universidade Federal do Rio Grande do Sul, Porto Alegre, 2017.

MANKIW, N. G.. Introdução à Economia. 5 ed. São Paulo: Cengage Leraning, 2009.

MARGULIS, S.. A regulamentação ambiental: instrumentos e implementação. IPEA, 1996.

MEIDEIROS, L. F. R.; MACÊDO, K. B.. Catador de Material Reciclável: uma profissão para além da sobrevivência?. Psicologia \& Sociedade, v18, n.2, p.62-71, 2006.

MEIRELES, V. K. A.. Gestão e tratamento dos resíduos plásticos produzidos pelo polo industrial de Manaus: Tecnologias e sustentabilidade. Dissertação (Mestrado em Ciências do Ambiente e Sustentabilidade na Amazônia) Universidade Federal do Amazonas, Manaus, 2016.

MONTEIRO, J. H. P.. Manual de gerenciamento integrado de resíduos sólidos. Rio de Janeiro: IBAM, 2001.

MORAES, J. L. M.. Pagamento por Serviços Ambientais (PSA) como instrumento de Política de Desenvolvimento Sustentável dos Territórios Rurais: O Projeto Protetor das Águas de Vera Cruz, RS. Sustentabilidade em Debate. Brasília, v.3, n.1, p.43-56, 2012.

MOTA, A. R. S.. Avaliação do Gerenciamento dos resíduos sólidos urbanos no município de Coari/AM. Dissertação (Mestrado em Ciências do Ambiente e Sustentabilidade na Amazônia) - Universidade Federal do Amazonas, Manaus, 2014.

MOURA, A. M. M.. O mecanismo de rotulagem ambiental: perspectivas de aplicação no Brasil. IPEA, 2013.

NUSDEO, A. M. O.. O uso de instrumentos econômicos nas normas de proteção ambiental. Revista da Faculdade de Direito da Universidade de São Paulo, v.101, p.357-378, 2016.

PEREIRA, H. S.; CAMARGO, T. R. L.. Bens, recursos e serviços ambientais: bases conceituais e redefinições. In: RIVAS, A.. Economia e valoração de serviços ambientais utilizando técnicas de preferências declaradas. Manaus: EDUA, 2014. p.304.

PIGOU, A. C.. The Economics of Welfare. 1920.

PINDYCK, R. S.. Microeconomia. 7 ed. São Paulo: Pearson Education do Brasil, 2010.

RIBEIRO, L. C. S.; FREITAS, L. F. S.; CARVALHO, J. T. A.; OLIVEIRA FILHO, J. D.. Aspectos econômicos e ambientais da 
reciclagem: um estudo exploratório nas cooperativas de catadores de material reciclável do Estado do Rio de Janeiro. Belo Horizonte: Nova Economia, 2014.

RIVAS, A.. Economia e Valoração de serviços ambientais utilizando técnicas de preferências declaradas. 2 ed. Manaus: EDUA, 2014.
SILVA, A. D.. Geotecnologias e a problemática dos resíduos sólidos urbanos em Tefé, AM. Dissertação (Mestrado em Ciências do Ambiente e Sustentabilidade na Amazônia) Universidade Federal do Amazonas, Manaus, 2009.

SOUZA JUNIOR, F. C.. Pagamento por serviços ambientais e créditos de lógistica reversa. Revista Jurídica, v.2, n.3, p.150184, 2018.

A CBPC - Companhia Brasileira de Produção Científica (CNPJ: 11.221.422/0001-03) detém os direitos materiais desta publicação. Os direitos referem-se à publicação do trabalho em qualquer parte do mundo, incluindo os direitos às renovações, expansões e disseminações da contribuição, bem como outros direitos subsidiários. Todos os trabalhos publicados eletronicamente poderão posteriormente ser publicados em coletâneas impressas sob coordenação da Cognitionis Publishing, da Companhia Brasileira de Produção Científica e seus parceiros autorizados. Os (as) autores (as) preservam os direitos autorais, mas não têm permissão para a publicação da contribuição em outro meio, impresso ou digital, em português ou em tradução. 